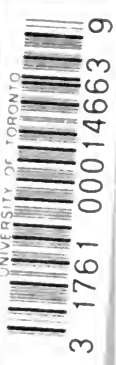

N

70

A 53 

ANNUAL PHILOSOPHICAL LECTURE HENRIETTE HERTZ TRUST

\title{
ARTISTIC GREATION AND COSMIC CREATION
}

\author{
By S. ALEXANDER
}

Fellow of the Academy

Read November 23, 1927 
N

70

A 53

समी : क 1980

1050824 


\title{
ANNUAL PHILOSOPHICAL LEGTURE
}

\author{
HENRIETTE HERTZ TRUST
}

\section{ARTISTIG GREATION AND COSMIC GREATION}

\section{By S. ALEXANDER}

Fellow of the Academy

Read November 23, 1927

PICTORIAL imagination is a wondrous blessing not 1 only for the lunatic, the lover, and the poet, but for the philosopher as well. Perhaps few philosophers have been devoid of it altogether, and nearly all persons who, without being philosophers by nature, attempt to think philosophically (and these are, I suppose, the majority of men, just as most men have the sense for beauty but only a privileged few are artists) possess it and are dependent on it. But here is the provokingness of it. Just when we reach ultimate problems or ultimate conceptions it deserts us. Either it is replaced by intellectual imagination or thought construction; and this is what happens to the philosopher proper; or it leaves us a prey to error or helplessness, which is often the case of the generality. For pictures are of the finite and the developed and of that which is distinct in its limited outlines. But they fail us when we touch the infinite or undeveloped and that which has no outlines but is the source of everything which has. And so a great imaginative writer like Plato, before he attained his full and abstruse and rigorous maturity, has recourse when he comes within sight of his ultimate questions to myth and symbol, glorious prefigurements of abstract conceptions like categories and numbers.

These rather trite reflections are suggested by the problem of creation, that is, of cosmic creation. For the creations we know are finite products of nature or manufacture 
or art. But when we ask ourselves about the creation of the world we stumble, because we carry these pictures about with us and we try to interpret by their help what is beyond the reach of pictures. Thus because for us a statue or a picture or a scientific theory or a steam engine is brought into being by a mind or spirit operating upon matter, or a great and beautiful fancy comes or seems to come out of our minds, we imagine a spirit which is an indefinite enlargement of ours, which educes the world from we know not where by the fiat of his will. Or we may even in our naïver moments imagine some man-like creator hewing the world out of some rough quarry, as drawn in a picture which used to delight me as a boy in Pouchet's Universe which I got for a prize. Strictly speaking, we cannot ask of the whole how it came into being, for all these conceptions, coming into being, production, causation, willing, decrees, belong to the parts of the world and not to the world as a whole. The philosopher Lotze is never tired of saying that to ask the reason why the world was created is a question mal posée. Yet the philosopher may expose the unfitness of the question as he will; the unregenerate man, and the philosopher himself, when he relaxes from his tension of thought, persists in it. He is not content to accept the world; it is so mysterious a thing that the world should be, not merely the sort of thing that it is in its details and its laws, but that it should be at all, that he finds himself unable to dispense with the imagination of a creating agency. And as if by some instinctive feeling he does not go on as he rightly should to inquire into the origin of this spirit-if God made the world, what made God? The obscure and correct sentiment that no further question can be asked leaves him content with the ultimate Spirit which is, and from which all existence flows. But using as he does imaginative ideas derived from finites, he is content, because happily for him he does not think, and he can explain neither how this immense finite which he calls infinite got there nor how it can produce the world. 
I too shall join the philosophers and shall try to show that our question is not how the world came into being, but what sort of a thing the world is in its ultimate and simplest nature, within which we may legitimately say that creation takes place and things are produced and events come to be and are caused. I am sure that if I say Spirit is there I cannot rest content with using this picture of the most developed thing we know, without asking how it came to be. But I know also how hard it is to avoid asking the question even if the elementary world is correctly conceived, and I too am beset with the pictorial habit of going outside the world as it were and asking for its author. It seems to me, therefore, useful for myself and perhaps for others to inquire first what creation is where we are familiar with it, and to use the answer to that problem to interpret what creation must mean when we speak of a creative principle in the whole world. It may be that to find the source of the world in a spirit is to make a mistaken use of the analogy of artistic or other finite creation. At any rate the first inquiry is feasible.

\section{I}

For the ways of the Universe may be past finding out, but the ways of art need not be, and it is a good rule that we should go to what experience presents to us, before we indulge in conjecture or hypothesis. I am not proposing to examine fully the nature of beauty, either what it is in itself or what the feeling of beauty is. And I am not going to raise the question whether nature or natural objects may not be beautiful of themselves without the need of an appreciative mind, whether that is to say beauty is not in beautiful natural objects themselves, a property of them independent of our human eyes and ears. I think myself it is not, and the mind is always there as a party to the beautiful situation. I limit myself to the beautiful in art, and there at least one thing seems to me clear, that in such objects spirit and matter are blended and at one. The 
object embodies the artist's thought or fancy, while the moulded object is aesthetically significant only to his appreciation, or of course in minor degree to that of the spectator whom in a manner he teaches to see with the aesthetic eye. More than once I have pointed out how in the beautiful object the significance is supplied in part from the artist's mind; how it is he who makes the flat Madonna seem, as Mr. Berenson puts it, a tangible threedimensional being, or who gives divine playfulness to the Hermes, or motion and dance to the motionless maidens in the picture of the Spring, or who finds the perfect, the only fitting word, to express a meaning that springs from him, in what manner we shall presently see. And I have contrasted the object of art with the mere percept where also half comes from the perceiver's mind and half from what he directly sees: the coloured moving shape is perceived to be a man, though sight alone without memory does not say so. The contrast, if I may repeat myself, is this: the characters we impute to the object perceived, if we perceive correctly, really do belong to the object and may be sensed there on proper occasion, the coloured shape is the visible surface of a man; but in the work of art there is always illusion: the Hermes is not divine but only seems so, and the girls in the Spring are not in motion. At the same time, I have added, the artistic illusion is unlike ordinary perceptual illusion, for that illusion disappears to better acquaintance, is recognized to be an illusion. Whereas the illusion is of the essence of the work of artceases, therefore, to be illusion and makes the object significant. Hence the Hermes which you see in the gallery or which the Greeks saw at Olympia is not a mere marble block, not even a mere block so shaped. Only to the aesthetic eye is it really divine or even really alive, and when you see it so you are in the aesthetic attitude. Hence as mere marble, so shaped, it belongs to the natural world; but as Hermes, the playful god, it has a new reality, compounded of the marble and the spectator's mind. This 
does not mean any mysterious blending of stone and mind, but merely that the stone has qualities which it only has so long as it is contemplated by the mind. This inner compenetration of the two is effected by the marble's being so shaped, so textured, so played upon with light and shade, or it may be so draped or even coloured. There was the artist's creation; he found by his hand this body to be the bearer of his thought. I pass deliberately over many points of interest or difficulty, in particular the sense in which the statue or picture is expressive. I add another illustration to drive in the main lesson that I learn. Take a beautiful portrait of an ugly person. The picture is beautiful, the real person represented is, let us say, repellent. The artist has seized the essence of the person's character and embodied it in the form of his ordered pigments, has made the form significant of, say, a noble character or at any rate a character that counts for something, even if bad or weak. He makes his subject significant and he has lent significance to his pigments out of himself and therefore signified himself as well; he has in expressing himself made his subject characteristic. Presently you meet the person and you recognize him to be the noble or characteristic man he is. He does not therefore become beautiful; he is still a man with a repellent face and an attractive character. If, after seeing his picture or for other reasons of your own, you see him beautiful, you are imposing upon nature the aesthetic interpretation. That is why I said a moment ago, that in my belief natural objects were not beautiful or ugly in themselves; there 's nothing beautiful or ugly, if I may parody Hamlet, but aesthetic imagination makes it so. ${ }^{x}$

The above statement, that the work of art implies, besides the material, imputation from the artist may seem less easy to justify in those works where, as for instance in certain paintings, the representative element is in abeyance in comparison with the formal one, or in music in which at first sight there is no human addition or subtraction. Yet I believe the statement is true even there. 
So intimately in the work of art are form and significance blended into one; and hence it is that different writers can say that form is the essence of art, or meaning (characteristic) is the essence of it.

But at this point I find myself confronted with a doctrine, which appears under different forms, that the embodiment of the work of art in external physical form, in stone or pigments or musical sounds or words (I mean of course spoken words, for mere writing or print is notation and nothing more), is unessential, a matter of technique. Even Wordsworth has given currency to this idea.

$\mathrm{Oh}$ ! many are the poets [he says in a famous passage of The Excursion] that are sown

By nature; men endowed with highest gifts,

The vision and the faculty divine,

Yet wanting the accomplishment of verse.

As if poetry lay in the poet's vision and the words were nothing but an added and not an intrinsic element. Nowadays it is often said that the work of art exists in the artist's mind as an image or intuition, and that since the image is his private possession it needs embodiment in physical form to give it publicity, to communicate it to others, and give permanence to the transitory mental existence, and that this is the sole purpose of technical embodiment in material. If this were true there would not be the fusion of external material and the artist's mind which I am suggesting is vital to art in all its forms, and the analogy of the arts would lead to a different result when used to illustrate cosmic creation.

Elsewhere ${ }^{\mathrm{I}} \mathrm{I}$ have given reasons for believing that this conception is mistaken and that the physical material work is organic to artistic creation. Artistic production is on a line with the other organic actions by which we become aware of physical things in perception. When I see a

${ }^{1}$ Art and the Material (Adamson Lecture), Manchester University Press, 1925; and Art and Instinct (Herbert Spencer Lecture), Oxford, 1927. 
colour, I am not first aware of the colour and then turn my eyes to it. On the contrary the coloured object by its action on my retina and my brain compels me to fix my eyes upon it, and in doing so I become aware of the colour. I do not first know and then act, I know through acting; the object is revealed to me because it wrings from me an appropriate action. Artistic production is of the same sort, but more complicated. For the practical actions we perform on physical objects are directed towards those objects: we alter them or, in cognition, attend to them. While in our artistic actions, in production, we create a new thing, the work of art. But the general character of the process remains the same. The subject-matter of the artist, the face he is painting, or the feeling, say of love, or the dramatic situation he is thinking of or is possessed by, throws him into a state of artistic excitement which issues in the act of speaking verse or painting the face or sculpturing the head in stone. The action is wrung from him by the subject-matter, through the excitement it produces, in the same way as turning his eyes to a colour or sniffing an odour by his nostrils is wrung from him through the nervous excitement the colour or odour produces in his brain. And just as the object known is revealed through the ordinary reaction to it; so the work of art is revealed to the artist himself through the productive act wrung from him in his excitement over the subject-matter. Accordingly, he does not in general first form an image (if he is a poet, say) of what he wants to express, but finds out what he wanted to express by expressing it; he has, in general, no precedent image of his work and does not know what he will say till he has said it, and it comes as a revelation to himself.

The only way to test this statement is by appeal to artists themselves. But in part I can refer you to such experience as any one may have of artistic production when he tries to write an essay or even a letter as well as possible. I will take two illustrations and put the question to you. The 
first is very familiar to you. I may say in practical prose 'I love you and always shall'. That is a practical proposition. It is a long way from that to Burns:

As fair art thou, my bonnie lass,

So deep in luve am I,

And I will luve thee still, my dear,

Till a' the seas gang dry.

Do you think the poet had first in his mind some vision of an eternity of love which would last till the seas dried up, or that in the aesthetic excitement of his feeling or thought about his feeling the thrilling words were out of him before he knew?

My second example is even more familiar and it is far graver:

And Ruth said, Intreat me not to leave thee, or to return from following after thee; for whither thou goest, I will go, and where thou lodgest, I will lodge; thy people shall be my people, and thy God my God. Where thou diest will I die, and there will I be buried; the Lord do so to me, and more also if aught but death part thee and me.

The writer's mind is occupied with thoughts and images of the devotion of the alien daughter to her husband's mother. Does he, playing with the pictures suggested by that devotion, merely translate the pictures into this perfection of words? Or does he in his artistic understanding of the passion of Ruth allow his artistic excitement to overflow at white heat into words which reveal to himself as well as to us the situations of life appropriate to her devotion?

Thus it is not true, as you might suppose from Wordsworth's words, that poetry lies in the vision and that putting into words is an added accomplishment. A man may have vision, even the most imaginative vision, of his subjectmatter, but it is only when that vision excites him into the more or less unreflective ${ }^{x}$ issue in words that he is a poet,

I I say more or less unreflective. For I do not mean that his action is absolutely blind. On the contrary there may be at the back of his 
and that depends upon far more than education in speech. Poetry exists in the spoken words, rhythmical and passionate and enchanted. It is they which contain and reveal the exact working of his mind; though words are no more poetry in themselves without their meanings than the vision of the poet about the subject is poetry without issuing in ordered speech.

There are, however, various reasons which may deceive us into supposing that the physical material is indifferent, a mere means of publicity, and that the work of art is finished in the imagination of the artist. In the first place, all artists in respect of certain parts of the work, and some artists in respect of the whole of it, anticipate the finished product in idea or imagination. There is no doubt of the fact, but the fact is misinterpreted if it is taken to imply that the physical execution is unessential. For the image of the product is to be distinguished from the image of the subject-matter however much thought and insight and vision gather around that subject-matter. The image of the finished product, of the picture or the poem or the statue, is the image of the product, it implies words or pigments or stone, and perhaps it involves also images of the very movements which the artist makes with his brush or chisel or his voice. The difference between artists who work in this way and those who do not is merely the difference between doing a sum in your head and on paper. The work of art is done in the head, but whether it is real pigments we deal with or imaged pigments is a matter of no importance. It is through experience of the actual pigments and words and stone that the artist can dispense with their actual presence. The real problem is how from

mind all manner of literary or other artistic experiences and learning, and the habitual correction by poets or painters of their work in subsequent versions is enough to show the part which reflection may play. Yet even when a poet corrects he is prompted by dissatisfaction with the existing word as an expression of his aesthetic emotion in its spontaneous action. 
his vision of the subject-matter the artist proceeds to his product; but whether that product is left in his head or he is aware of it only by seeing or hearing the actual (as distinct from the imagined material) is insignificant. In the first case, he does but transfer into physical reality what is imaged as physical reality. The image which he forms in the first instance of the picture or the statue or the verse is wrung from him by his artistic excitement about the subject-matter.

Another kind of misinterpretation arises in this way. An artist, without imagining the product, the painting, \&c., may form a vivid and detailed image of the subjectmatter, and he may fancy that he is merely transcribing this image in much the same way as a man of science transcribes exactly the facts he is engaged upon. It is not so easy to fall into this deception with painting or sculpture, for the more suitable the vision is for mere imitation the more it approximates to an image of the finished product, that is, the case we have just dealt with. But in poetry, the artist sometimes does appear merely to imitate in words or describe as it were in a transcript the image in his mind; and so it might be supposed that it is really this vision of his of the subject, the moaning of the doves and the like, that is the poet's model which he faithfully describes. Now in the first place such imitative or purely descriptive passages are never the highest poetry, nor is descriptive music the highest music. And in the next place, the words never are purely a transcription of an imagined scene, but in the intoxication of the picture the poet as his words flow alters the picture from which he works under the influence of the words, as in the enchanting picture of Eden in Paradise Lost. Out of the wealth of images which arise in his mind he has to select and amplify and modify to suit the condition of his mind, and the history of his imagination is never distinct from the history of his speech, but the two are moulded together one upon the other, and the images are half-spoken words, and moreover are 
subjected to the needs of language, at the behest of rhythm or rhyme. ${ }^{x}$

We may safely then conclude that the material of the work of art is no mere technical ingredient but vital: that poetry is words of a certain sort and a painting pigments, and a statue physical stone, idealized to contain the artist's meaning or his passion, and chosen to be such and such, this word and not that, this shade and not that, this outline and not that, because thus and thus only can the subject-matter receive the significance he imparts to it.

I have spoken of the artistic excitement without attempting to describe it, and it will be as well to do so shortly, ${ }^{2}$ because recent theories about the motive which produces art lend colour to the notion that art is the translation of images into material form. The aesthetic excitement is not to be identified with the practical passions which the subject-matter may arouse in the artist's mind, which overflow into words, as anger for instance into expression of hate. The artist may or may not feel such emotions; in lyrics he does, in drama he need not. It is almost a commonplace that poetry or painting which does no more than excite in the hearer's or the spectator's mind such emotions is in itself no more than story-telling or illustration, which by itself has not artistic but only practical value and may easily degenerate into sentiment. The passion proper to the artist and communicated to others in minor degree, the aesthetic impulse with its aesthetic emotion is of a specific sort. It is, I believe, the formal impulse of constructiveness, which is an outgrowth from or a modification of the instinct of constructiveness which we share with such animals as the bee, the beaver, or the bird which sings for courtship or builds a nest for its young. It is so overlaid with human characters, so refined, as to seem remote

I Some further discussion of these topics will be found in a paper on 'The creative process in the artist's mind', British Journal of Psychology, vol. xvii, Pt. 4, April 1927.

3 Cf. Art and Instinct for fuller treatment.

xuI 
from its instinctive origin. In particular it has become diverted from practice and contemplative. When the instinct of constructiveness seeks not practical gratification but is satisfied for its own sake; when the maker beholds his work and sees that it is good, the constructive instinct has become aesthetic and the work which satisfies it is beautiful.

The artist then works upon his clay or words or pigments under the compulsion of this impulse, but with his eye directed upon his subject-matter, which partly is present to his mind in all manner of conscious perceptions, images, and thought, and partly affects him unconsciously. Of these unconscious elements, some are the familiar subconscious motives which enter into ordinary waking experience; but some may well belong to that deeper unconscious which according to a well-known discovery is revealed in the imagery of dreams. Indeed, it has been suggested that art is nothing more than a dream expressed in external form through the strange gift of translation which the artist possesses, that for instance the moving force of Dante's art is his love for the real Beatrice Portinari. I submit that his love would account for the thoughts of Beatrice which are woven into his poem but not for the art of it. Such motives belong to the subject-matter. They may appear as images in dreams, but dreams are not in themselves art but only reveal the stirrings in the mind of the dreamer which are connected with the topic of his art. Impulses which might appear in his dreams as imagery are in his waking life only part of the background of his topic, exercising doubtless an important, even perhaps the chief, influence over the materials which go to constitute his subject-matter. They do not in him take the form of imagery, but are unconscious movements in his brain which have no conscious object while he is not dreaming. There is, I suspect, a confusion in this doctrine between the artist's mind when he is at work upon his art and his mind as it might be if he were dreaming. In either case the 
unconscious elements belong to the subject-matter and not to the art. The artist must have something upon which to work, but his artistic impulse lies in the choice of his materials, to which there corresponds in the work of art its design which gives it form. ${ }^{\text {I }}$

\section{II}

This digression has been long, but it has removed from the work of creative imagination the last trace of accidental elements; that product is a material thing of speech or instrumental sounds or solider pigments or stone, dyed through and through with meanings, and these meanings sustained and supplied by the appreciating mind. With this conclusion we can proceed by the help of analogy to the cosmic problem. But what might seem to the hasty glance the natural application of the analogy, to suppose a creator, spiritual and more than man, fashioning a material which he finds or even creates from himself, is in reality to misuse the analogy, by exploiting its accidental features and neglecting the essence. The essence of the work of art is that in it creative mind and the material are indissolubly fused. That this fusion is the meeting of two separate beings, the man who creates and the material which receives from him its form, is indeed vital to the artistic situation, but arises from the finitude both of the creator and his material.

Now the use of an analogy lies in its relevance; it misleads if it is not adapted to the new situation in which it is employed. It was from such neglect, that, to take an illustration from psychology or biology, instinct was so long misunderstood as proceeding from explicit purpose. Closer inspection, freed from the anthropomorphic or pathetic fallacy, showed that below the level of strict purpose there

I The problem is discussed in Mr. J. M. Thorburn's suggestive work Art and the Unconscious, London, 1925. He has a felicitous if paradoxical way of connecting art and dream; he says the artist's external material, clay or stone, hypnotizes the artist into sleep. 
was something which simulates purpose, or of which purpose is an explicit form, which is nothing more than the pre-arrangement by which one step in a complex of movements prepares, and flows continuously into, the next. We may call such purposiveness if we choose unconscious purpose, but we only substitute a phrase. But when we have learnt that actions may conduce to an end which is not foreseen, we cease to gape at the exceeding skill of animals lower than ourselves and still more to suppose them endowed with these powers by an all foreseeing Creator; we adopt the modester and not less reverent method of seeking to understand them and their place in nature. The hardest thing is to understand that which is simple. We may and must approach it from the complex. But if we identify the simple with the complex we miss the sense of both. We use our knowledge of the complex rightly in interpreting the simple when we discount the circumstances which make it complex. And this is difficult and requires some pains.

In applying the analogy of the arts to the world we must then discount the finitude of the partners in the transaction, and when we do this the application of the analogy is exactly counter to the notion of a mind or spirit which precedes the world and creates it. For in the first place the infinite, being infinite, can have nothing outside itself upon which to work as an artist works on his material. On the other hand what is vital to art is not, in this connexion, the separateness of the artist and his work before the work is done but their fusion when the artistic product is achieved. Strip off then the finitude involved in art; we must look then to the world in its simplest expression, and there we find something which corresponds to the essence of art, the complete fusion in it of something that corresponds to mind and something that corresponds to material. To be stricter, we find rather something in which there is no fusion at all except metaphorically and by legitimate analogy; something which is anterior in thought to fusion, 
but in which thought can detect these different aspects. It is itself uncreated but is merely there. In it as in a matrix are formed the finite things which are said to be created and to have a beginning, which acquire a semiindependent existence, like crystals in the mother liquid in which they are deposited. It is, in the old phrase, cause of itself, causa sui, self-created. But though uncreated, it is creative, in the sense that these crystals or embryos grow within its womb; and it must contain in itself some principle or character which is manifested in this growth. It has no purpose, but its creativeness comes to fruition in certain finites which possess true purpose, and we should expect to find, as we do, gradations between what appears as mechanical action at one end and true purpose at the other. There is no creator of it except itself; but it is the creator of all finites that come into being within it. But to say that the world has no Creator is not to say that it has no God. On the contrary the whole hierarchy of things cries out for a form of created existence beyond what is hitherto created, and the whole universe regarded as engaged in producing this higher form of existence is God. God's deity then is created; but the whole world is divine as being big with this created quality, and God, therefore, though not the creator of the Universe, is, so far as he is identical with the universe, creator of all the beings within it.

Such is the true application of creation in the arts by analogy to cosmic creation, and it is just the opposite of what might seem at first blush the natural application of it. There is no room for any spirit which precedes the world, not even to say as Goethe does, in that metaphysical poem about the birth of colour in the Zuleikah book of the Westostlicher Divan, that it lay in the eternal bosom of God; there is but the universe itself, whose name in one aspect of it is God. But such a simplification removes also, or at least helps us better to withstand, the temptation to ask for the origin of the world from something other than itself, 
a temptation against which, as I said, the philosopher is no more proof than the unphilosopher. For we who ask the question are products of the process of creation, and we dare not speak of the universe in terms of its parts. But if we think of the world as primordially a spirit, and not less of a spirit than ourselves but more of one, as we necessarily do if we indulge in such descriptions as I have named, we are not securing simplicity, but only interpreting the simple by the complex. We merely substitute for the complex human spirit which we know another complex spirit which we do not know. It is as if we were to seek simplicity in our lives and habits, not by dispensing with unnecessaries but by returning to staining our skins with woad or living on roots and cooking our game in a cave. We only vary our accidentals, choosing a more inconvenient form of them, which we imagine simpler. But the Universe in its basal character is fundamental to every form of product which grows up within it, and if we try to get down to fundamental simplicity it must not be in terms of the mind we know. The simple world may still contain its analogue to mind, but that mind will be more and not less elementary than ours. If we thus bear in our thoughts that we are units in the outgrowth of the fundamental stuff of the world, we shall accept that world as above our questioning, like Shakespeare in Matthew Arnold's sonnet: 'Others abide our question, thou art free.' We may question of ourselves and all other created things, but the world itself is subject to none of our ideas but is the source of them.

The only question then that is left for the metaphysician is of what nature is this primordial world which literally underlies the universe we know; which is no fancied Absolute that, bare itself of all natural qualities, blossoms out into them as its appearances; which is being itself, and neither cause nor substance nor one nor many nor things, but contains numbers and causes and things within itself, as real features or parts of itself and not merely as emitted 
from itself into precarious appearance. The answer to this question is open to much doubt. It has been suggested that the stuff of the world is space-time itself, which physicists hold to be no mere receptacle of things, no mere form of mind but something quasi-physical. And I have dared to think that the matter which the physicists postulate in addition is not fundamental but itself a growth within space-time. Such a stuff may also be described as motion; happily or not I must not judge, for at least this primordial motion is not the motion of material particles, which is derivative. Motion understood as the primordial stuff is what change becomes if you strip from change the notion of some quality which is replaced by some other quality. Rather the name is used to indicate that passage of nature of which Mr. Whitehead speaks, and to insist that the stuff of things is events and groups of events, not something fixed and resting but something which contains in itself a principle of unrest.

As the work of art is the fusion of spirit and matter in finite ingredients, so within this space-time, which is below fusion, there is an element which corresponds to spirit and one which corresponds to matter, and these are respectively time and space. Time is as it were the mind to the body which is space. Or since we are helping ourselves out to describe the simple by the complex (though without the fallacies which pictorial imagination introduces) let us rather say that in spirit and body as we know them, whether in an organism or in the new creation by man which art supplies, spirit is the time, and body or material the space element in these highly developed creations of the world process. Our life is the time of our body, which is the space of our life; only for brevity's sake I have to omit the qualifications which are needed to make this proposition true.

Space and time are, however, indissoluble ingredients of the one reality which is space-time, and neither has an existence independent of the other. Each involves the other 
Though I cannot make good this statement here, it is in keeping with the recent physical conceptions; and it serves me in passing on to two points of the first importance. One of them I have already indicated. Since space cannot be without time, it follows that all stable things, which we are apt to regard as fixed things which may undergo changes, are but groups of motions or changes; that as a river preserves its form while in reality it is a stream of changing matter, so the material and other things which crystallize within the matrix of space-time are but groups of motions which preserve their form. So far as regards the living organism this would be readily accepted, and certainly by those who have felt the force of Mr. J. S. Haldane's account, based on the processes of respiration which he describes summarily in his work Organism and Environment (Yale Press, 1917), of how the structure and constitution of one part of the system depends upon the needs of the other parts. 'The structure', he says, 'is only the appearance given by what seems at first to be a constant flow of specific material beginning and ending in the environment' (p. 99). The stress lies here on the word 'flow'. Extend this notion downwards from organic to material things (which Mr. Haldane would perhaps not be willing himself to do) and you have the conception of things, whether living or not, as stable configurations, as a whole of movements or, if you care to use organic terms, of functions.

The second point is less obvious and more contentious, but it is to my mind not less clear. The primordial world which is without parts breaks up into parts held together within the stuff of the world which I must not call the one stuff, for fear of describing the creator in the language of the creature. It germinates into the infinite variety of things in all their grades of development. This impulse of creativeness I call the nisus of the universe, borrowing an idea from Spinoza and agreeing, as I think, with the spirit though not all the details of Mr. Bergson's élan vital. This 
nisus not only leads to the formation of things and to the sustainment of them, but impels the world forward towards new creations, bringing forth the new out of the bosom of the old. It creates chemical bodies and keeps up their form by the stability of their functions; but also, and this is perhaps more striking, drives on 'the chemic lump', in Emerson's words, to 'ascend to man'. Now this nisus is the element of time in the primordial world, its principle of mobility and restlessness. Yet lest it should be thought that space is something upon which time works and that time is the creator, we remind ourselves that time could do nothing, could not even be, except for space; which is thus also creative for it is not without the element of transition, and space by itself is but the totality of events considered without their movement.

This nisus is no effort on the world's part to extend its bounds; such a notion is unthinkable, for the universe is boundless; but a ceaseless impulse to produce parts and alter the grouping of events into things. Things, we have seen, are clusters of events; and the world's nisus sustains some of these clusters and produces others new by fresh combinations which it strikes out in the heat of its desire.

\section{III}

The discussion of this topic would lead me too far. But I may endeavour here to remove a possible misconception. This primordial world of space-time is not the dance of atoms imagined by Epicurus or Lucretius. Atoms are a late and complex product of history, manufactured articles in a sense different from that of Clerk Maxwell in his famous phrase. They have long since been displaced in physics by something more elementary, and shown to be comparable to stellar systems, which may even in their internal coherence seem to adumbrate organic life. They suggest affinity with higher creations, and that affinity would, if what I have conjectured is true, stretch downward to more primitive creations and even to space-time itself 
and its spatio-temporal component events, which have in them all, in time some forecast of mind and in space of matter. I mention this because it bears upon a prejudice entertained by so many, to which in particular Lord Balfour has given so distinguished an expression, that only ordinary theism can account for the values of beauty, goodness, and truth. The prejudice against our descent from apes which was provoked by the Darwinian theory no longer exists; we are even proud that we are so much better than our fathers. But it is replaced by this new prejudice or is revived in it under a different form. Half the repugnance that is felt to the affiliation of values with a world which did not already imply them is removed by removing the fancied antithesis of the mechanical or material and the spiritual. The mechanical is penetrated with time which is the predecessor of mind, and the mechanical is not opposed to life so much as that it is simpler, more uniform, and of more routine a character; so that the functions of life when they harden into custom recede into the material order, as the mental in turn hardens with custom into the physiological and unconscious. As elements of the world which are not included in the mere material order arise and introduce the beginning of freedom, the automatic life of matter is replaced by the less simple life, or living beings, and new elements of freedom enter further with the life of spirit.

For my own part I believe that, in the end, a theistic conception of God's deity is demanded by the facts of nature. But to hold that value demands a theistic creator appears to me to rest upon leaving the notions both of a theistic creator, with design and reason, and of value as well, in the obscurity of neglected analysis. The connexion of God with his created world is left vague admittedly, and that of value at least is surrounded with the nimbus of emotional fervour which treats examination of it as a depreciation of its real worth. We forget that value is a human invention, not in the sense of an artificial product, 
but of an effluence of man's nature, and if the body is descended from the apes so may value be rooted in organic analogies. A successful genealogy of value would no more alter its preciousness or sacredness than material objects were altered, as Berkeley pointed out, by his proposal to treat them as ideas. If value were not an expression of man's whole nature, in its relation to its environment both natural and social, something might be said for an appeal to some divine forethought and wisdom. But the impulse to do, to learn, and to create, are parts of the human equipment; the values are but the discovered scale of the embodiment of these impulses in judgements of act, in knowledge, and in creative art.

Moreover when they are considered in relation to the history of the animal man, they are seen not to be unique things in the world, but foreshadowed. Natural selection is particularly made the stone of stumbling in the attempts to regard value as, like other things, historical and evolved. The exact share of natural selection in natural history has now become controversial. But so far is natural selection from being incompatible with value that value is rather one way of describing an essential feature of natural selection. For value always rejects unvalue and is established by that process. And it is precisely by that rejection that, so far as natural selection holds in nature, organic forms are stabilized under their conditions of value. Natural selection is in fact the history of value in the organic world. How much farther down it extends, what analogues it has in the mere material world, it would perhaps be presumptuous to attempt to say. But in the organic world, every time that a variety excels its rivals in the struggle it so far establishes an infra-human value. This does not mean that beauty and truth and still less right are made by force. Might is not right; that halftruth has brought down a great nation; pray God it may not bring down another. But right is might; only, because that proposition is so easily misapprehended, it were better 
replaced by the less pointed one, that right is what is suited to prevail in the judgements of men. And if we have faith that the world works out its salvation and not its destruction, we shall be apt to believe that what so prevails is rooted in the nature of things, including men. At least if it is not so, we act as if it were so; and if the pursuit of this faith leads to our extinction, value will perish with us.

The marks of providence and design in nature and in man which are thought to demand a provident and all purposing creator of the world do not weaken but rather enhance the conclusions which follow ultimately from considering the analogy of the arts. Providence is in the main the name for the fact that the result of man's purposes is something which he never purposed. 'Nothing', says Victor Hugo, 'needs so much to be foreseen as the unforeseen.' But we do not foresee it; we hardly foresee what can be foreseen, else how could the statesmen of Versailles have forgotten the nemesis that dogged the career of Napoleon, and forgotten the treatment of the Southern States after the Civil War by the Northern States of America? And since the unforeseen is not foreseen but happens, we attribute it to Providence. But the procedure of the artist, if rightly interpreted above, may teach us that there the work is not foreseen, but the artist is driven on from behind by his excitement and reveals to himself in the end the consummation of his desire. So far as he does not forecast exactly the product itself, his action is blind. If revelation depends on a purpose partly blind where there is real purpose, why should we shrink from the idea that the so-called blind action of matter or of living creatures below man's level may produce a form of existence, as they do, higher than or at least other than themselves? The adjective blind is in fact a misnomer. Matter is blind to what succeeds matter; but so are we to what shall succeed us. Yet each grade of existence has the vision which is relative to its estate: the animal which does 
not foresee its end is not blind to the means by which the end will inevitably come. From the relative vision of matter, treading its accustomed round, may arise the relative prevision of man.

Neither does the appearance in the world of design, by which creatures do not so much secure their ends as subserve the ends of other living things, require an all foreseeing purpose in a prevenient God. Hardly any can have escaped the reflection that since the higher organisms can live only by making use of the lower ones, only those higher beings maintain stability for which the lower are apparently created. Here once more we dare not gape at the wonders of purpose, but ask its lineage. When we do so we discover that it arises out of failure and is removed by success. It means not preordainment but the want of it. When the animal misses his 'end' he tries, in his excess of uneasiness, random or undirected movements, impelled thereto by the compulsion of his nature not to rest till the end is secured. The dog learning to carry his stick through railings is the familiar example, improved so often by American psychologists by delicate problems set to other and less appealing creatures, rats and mice and cats. Within the limits of their plasticity animals can vary their habitual instinctive acts. Suppose now the advent of genuine ideas as in man. The devices which the animal strikes out in the urgency of his desire become purposes, and when crowned with success subside and lay the foundation for other purposes. Thus purpose is one and the highest form of the consequence of failing adaptation, and it is the method under such circumstances of successful adaptation. It remains, therefore, as true as when it was said by Spinoza that to attribute an all-foreseeing purpose to God is to attach to him not perfection but defect. To accept purpose as the attendant in a conscious being capable of ideas of maladjustment is to place it in its descent from animal purposiveness and to suggest that if aggregations of material atoms do not exhibit purpose that may be 
because their complexity is insufficient to admit plasticity, and they require for sustainment no degree of freedom.

If these considerations are sound, artistic creation, so far from being the prototype of cosmic creation, is itself a late product in the growth within the universe of the various levels of existence in which the nisus of space-time takes effect; is an incident in the life of the highest existence known to us. The questions which are raised by the stratification of the world of finites into levels which in Mr. Lloyd Morgan's phrase 'emerge' I must not discuss here, having, indeed, done so elsewhere. I add only the remark that the conception of the nisus, which cannot be supposed to cease with the attainment of man, points to a higher form of existence and suggests an alternative theism. Instead of the vague notion which misinterprets the analogy of artistic creation of a theistic creator which works from behind with intelligence and purpose, it substitutes the notion of a higher being or phase of being, itself a cosmic product, the idea of which impels the possessors of that idea forwards, and in that sense draws them on from in front. 



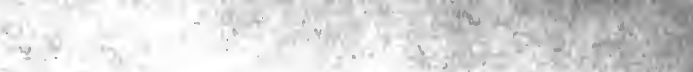

$2 y$

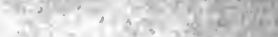

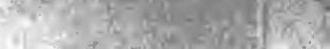

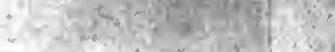

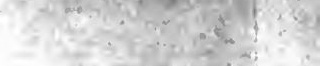

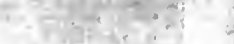

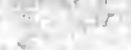

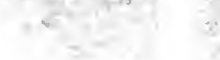


,

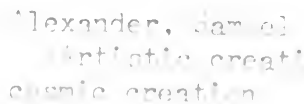

$?^{7} ;$

PLEASE DO NOT REMOVE CARDS OR SLIPS FROM THIS POCKET UNIVERSITY OF TORONTO LIBRARY 
